\title{
Liver aspiration in the diagnosis of hepatocellular carcinoma in the Gambia
}

\author{
ANDREW AJDUKIEWICZ, ${ }^{*}$ ANDREW CROWDEN,† ELIZABETH HUDSON,‡ \\ CHARLES PYNE§
}

From the *\$Medical Research Council Laboratories, Fajara, Banjul, and the $\nmid$ Royal Victoria Hospital, Banjul, Gambia, West Africa, and the $\ddagger$ Department of Histopathology, Northwick Park Hospital and Clinical Research Centre, Harrow, Middlesex

SUMMARY Fine needle aspiration was used for the cytological diagnosis of hepatocellular carcinoma in 151 Gambian patients. Of 133 with hepatic tumours a correct positive cytological diagnosis was obtained in $116(87 \cdot 2 \%)$. This simple test was a safe and accurate diagnostic procedure. It is particularly suitable for use in countries where medical resources are limited and hepatocellular carcinoma is prevalent.

Hepatocellular carcinoma accounts for about half of all cancers diagnosed in West African men.' At the Medical Research Council Laboratories in the Gambia, the diagnosis of hepatocellular carcinoma is supported by serum $\alpha$-fetoprotein estimations. During 1979 and 1980 liver scanning using a Hybrid scanner was used in these patients. ${ }^{2}$ Since 1979 , fine needle aspiration of the liver has been used for cytodiagnosis. Experience of fine needle aspiration on 151 Gambian patients is reported here.

\section{Patients and methods}

The 151 patients were investigated because of a clinical suspicion of hepatocellular carcinoma or to exclude hepatic malignancy. There were 125 male and 26 female patients. Apart from two girls aged $3 \frac{1}{2}$ and 11 years, the patients were between 18 and 70 years.

The procedure was explained to the patients with the help of an interpreter. They lay supine and a lumpy and irregular part of the enlarged liver was selected. The aspirations were done subcostally in the right upper quadrant of the abdomen, except in one patient in whom the liver scan indicated that an intercostal route would reach the tumour. The overlying skin was cleaned with methylated spirit and sprayed with ethyl chloride. An 18-21 gauge needle

Accepted for publication 24 October 1984

*Present address: Clo Ministry of Health and Medical Services, PO Box 349, Honiara, Solomon Islands. and $20 \mathrm{ml}$ syringe were used. With the patient holding his breath either in inspiration or expiration, the needle was inserted into the liver and aspiration was continued for 2-3s. Suction was released and on withdrawal of the syringe the contents of the needle were gently expelled on to slides and spread in the same way as a blood film. The syringe and needle were washed with physiological saline and the washings were centrifuged. The pellet was then resuspended in about $2 \mathrm{~cm}^{3}$ of physiological saline, transferred to disposable haematocrit tubes, and recentrifuged at $3000 \mathrm{rpm}$ for $5 \mathrm{~min}$, and then thin films were prepared from the buffy coat layer. These were fixed in methanol and stained with Leishman's or May-Grunwald-Giemsa stain. The two girls aged $3 \frac{1}{2}$ and 11 years were sedated before liver aspiration.

Serum $\alpha$-fetoprotein estimations were performed in all the patients by radioimmunoassay. During the first two years of this four year study these were done in the Department of Obstetrics and Gynaecology at St Bartholomew's Hospital (Professor T Chard). ${ }^{3}$ Subsequently, only hepatitis B surface antigen ( $\mathrm{HBsAg}$ ) negative sera were tested at St Bartholomew's Hospital. HBsAg positive sera were tested in the Gambia using Amersham kits.

In 44 patients who presented in the early part of the study an isotope liver scan was performed using a Hybrid scanner. ${ }^{2}$ Restricted facilities excluded histological biopsy as a routine procedure, but Menghini needle biopsies were obtained from 10 patients. The presence of ascites and the contribu- 
Table 1 Cytological diagnosis of 151 liver aspirations obtained over a four year period

\begin{tabular}{|c|c|c|c|c|c|c|c|}
\hline \multicolumn{2}{|c|}{ No performed } & \multicolumn{6}{|c|}{ Diagnostic category } \\
\hline & & \multirow[t]{2}{*}{ Inadequate } & \multirow[t]{2}{*}{ Benign } & \multirow[t]{2}{*}{ Atypical } & \multicolumn{3}{|l|}{ Malignant } \\
\hline & & & & & Anaplastic & $\begin{array}{l}\text { Consistent with } \\
\text { hepatocellular } \\
\text { carcinoma }\end{array}$ & $\begin{array}{l}\text { Diagnostic of } \\
\text { hepatocellular } \\
\text { carcinoma }\end{array}$ \\
\hline $\begin{array}{l}1979 \\
1980 \\
1981 \\
1982\end{array}$ & $\begin{array}{l}23 \\
37 \\
33 \\
58\end{array}$ & $\begin{array}{l}0 \\
1 \\
0 \\
0\end{array}$ & $\begin{array}{r}7 \\
3 \\
6 \\
11\end{array}$ & $\begin{array}{l}0 \\
2 \\
3 \\
1\end{array}$ & $\begin{array}{l}1 \\
2 \\
0 \\
4\end{array}$ & $\begin{array}{r}9 \\
8 \\
9 \\
20\end{array}$ & $\begin{array}{r}6 \\
21 \\
15 \\
22\end{array}$ \\
\hline Total & 151 & 1 & 27 & 6 & 7 & 46 & 64 \\
\hline
\end{tabular}

tion of ascitic fluid cytology to the diagnosis was reviewed for 89 of the patients with hepatocellular carcinoma.

The slides of liver aspirate and ascitic fluid were prepared, stained, and mounted in the MRC Laboratory in the Gambia and posted to Northwick Park Hospital for cytology reporting. Specimens from patients known to be $\mathrm{HBsAg}$ positive and from patients whose antigen status was unknown were packed separately from specimens from $\mathrm{HBsAg}$ negative patients and treated in the laboratory as Class B1 pathogenic material. ${ }^{4}$ These slides were immersed in activated glutaraldehyde for $20 \mathrm{~min}$ to inactivate any hepatitis antigen with which they might have been contaminated.

\section{Results}

\section{DIAGNOSIS}

The liver aspirations were obtained from 151 patients over a period of four years. The cytology was reported without knowledge of the $\alpha$-fetoprotein result in all except the first $10-20$ cases. The cytology reports were classified into three negative categories-inadequate, benign, atypical-and three positive categories - anaplastic, consistent with hepatocellular carcinoma, and diagnostic of hepatocellular carcinoma (Table 1).
The one inadequate sample resulted from an aspiration in which the syringe filled rapidly with 5-10 $\mathrm{cm}^{3}$ of blood. The needle had been directed at a filling defect seen on the liver scan of a patient who had clinical signs of malignant disease but a negative $\alpha$-fetoprotein result. The procedure was not repeated in case it should produce more serious haemorrhage.

Benign cells only were reported in 27 cases. Eight of these had the diagnosis of hepatocellular carcinoma supported by positive serum $\alpha$-fetoprotein results (5) or filling defects in the liver scan and relevant clinical signs (3). Fifteen patients had benign disease, two had metastatic carcinoma, and two had obstructive jaundice without evidence of hepatic tumour.

Atypical cells without definite cytological evidence of tumour were seen in six specimens. Four of these contained only a few abnormal cells which were considered insufficient evidence for diagnosis. The other two contained large numbers of well differentiated hepatocytes, but a distinction between hyperplasia and well differentiated hepatocellular carcinoma could not be made on morphological grounds. All six patients had hepatocellular carcinoma confirmed by positive $\alpha$-fetoprotein results (5) or a filling defect on the liver scan (1).

The 117 positive cytology reports were divided

Table 2 Value of liver fine needle aspiration in the diagnosis of hepatocellular carcinoma in 125 patients, 49 of whom were $\alpha$-fetoprotein negative

\begin{tabular}{|c|c|c|c|}
\hline Cytology & No of specimens & $\alpha$-fetoprotein negative & $\begin{array}{l}\text { a-fetoprotein pasitive } \\
(>1000 \mathrm{\mu g} / \mathrm{ll})\end{array}$ \\
\hline $\begin{array}{l}\text { Benign } \\
\text { Atypical } \\
\text { Anaplastic }\end{array}$ & $\begin{array}{l}8 \\
6 \\
2\end{array}$ & $\begin{array}{l}3 \\
2 \\
0\end{array}$ & $\begin{array}{l}5 \\
4 \\
2\end{array}$ \\
\hline $\begin{array}{l}\text { Consistent with hepatocellular } \\
\text { carcinoma }\end{array}$ & 45 & 21 & 24 \\
\hline $\begin{array}{l}\text { Diagnostic of hepatocellular } \\
\text { carcinoma }\end{array}$ & 64 & 23 & 41 \\
\hline Total & $125^{*}$ & 49 & 76 \\
\hline
\end{tabular}

${ }^{*}$ One inadequate fine needle aspiration, three metastatic carcinomas, and four anaplastic tumours of uncertain histological type are excluded from this table. 
Table 3 Comparison of fine needle aspiration cytology with histology of 10 liver biopsies

\begin{tabular}{|c|c|c|c|}
\hline \multirow[t]{2}{*}{ Cytology } & \multicolumn{3}{|l|}{ Histology } \\
\hline & $\begin{array}{l}\text { Hepatocellular } \\
\text { carcinoma }\end{array}$ & $\begin{array}{l}\text { Metastatic } \\
\text { adenocarcinoma }\end{array}$ & Benign \\
\hline \multirow{4}{*}{$\begin{array}{l}\text { Atypical } \\
\text { Anaplastic } \\
\text { Consistent with hepatocellular } \\
\text { carcinoma } \\
\text { Diagnostic of hepatocellular } \\
\text { carcinoma }\end{array}$} & $\underline{2^{*}}$ & $\overline{1}$ & 二 \\
\hline & - & 1 & - \\
\hline & 2 & - & 1 \\
\hline & 4 & - & - \\
\hline
\end{tabular}

*Both well differentiated hepatocellular carcinoma on histological biopsy.

into anaplastic (7), where no opinion could be given on the tumour type, consistent with hepatocellular carcinoma (46), where some of the tumour cells bore resemblance to hepatocytes, and diagnostic of hepatocellular carcinoma (64), when there was a strong resemblance to hepatocytes. The seven patients reported as anaplastic tumour included two hepatocellular carcinomas and one metastatic adenocarcinoma, which were confirmed by histological biopsy, and four patients in whom the tumour type was not identified. All the 64 patients with cytology diagnostic of hepatocellular carcinoma followed the expected clinical course of the disease. Forty one were $\alpha$-fetoprotein positive but 23 were $\alpha$-fetoprotein negative (Table 2). Among the 46 with cytology consistent with hepatocellular carcinoma one patient survived and a subsequent histological biopsy did not show any evidence of tumour. The cause of his right hypochondrial pain and hepatomegaly remain unknown, but it is

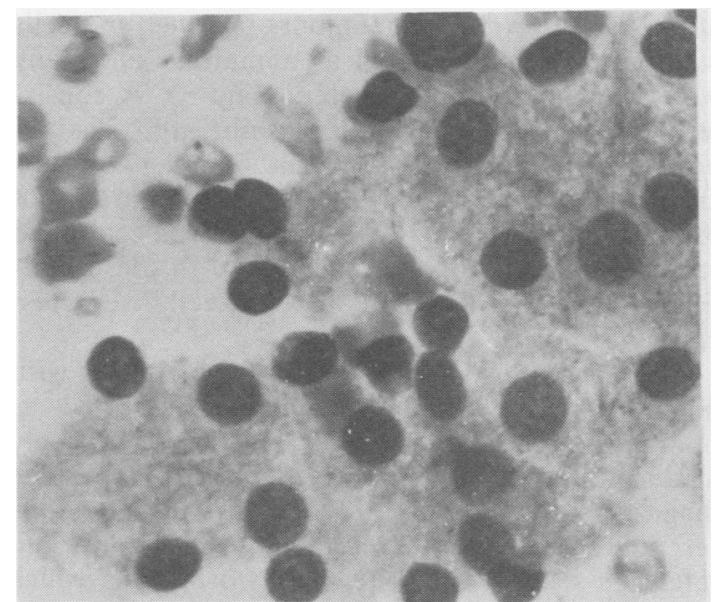

Fig. 1 Benign hepatocytes in a fine needle aspiration. A monolayer of polygonal cells with uniform nuclei and granular cytoplasm. Leishman. Original magnification $\times 160$. Enlarged $\times 5$. accepted that the cytology report was a false positive. The remaining 45 patients died of the disease.

Aspirates from four patients appeared macroscopically to consist of necrotic material and inflammatory exudate. Microscopy showed hepatocellular carcinoma cells as well as inflammatory exudate. One of these patients who had a fever was treated with metronidazole and showed considerable improvement, but a second liver aspiration confirmed the diagnosis of hepatocellular carcinoma. The results of amoebic fluorescent antibody tests received subsequently were negative for all four patients, who eventually succumbed as a result of their liver tumours.

Table 3 compares the cytology with the histology of the 10 biopsies. The biopsies confirmed hepatocellular carcinoma in eight patients. Two patients whose aspiration cytology was equivocal (atypical) and whose serum was $\alpha$-fetoprotein negative had histological reports of well differentiated hepatocellular carcinoma. One patient had metastatic adenocarcinoma and one biopsy, which was

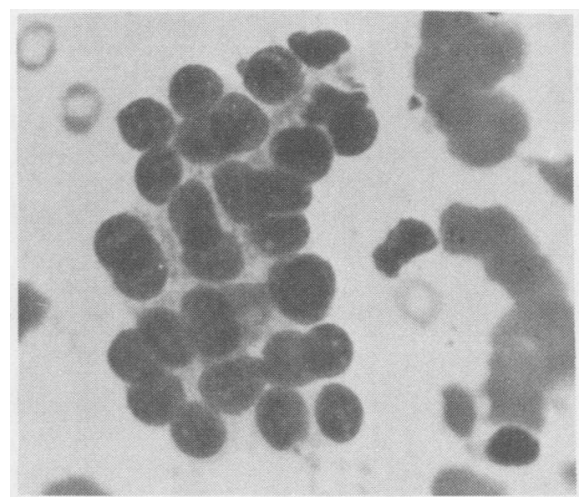

Fig. 2 Bile duct epithelial cells which characteristically appear as small clusters of uniform cells with little cytoplasm. Nucleoli are not usually seen. Leishman. Original magnification $\times 160$. Enlarged $\times 5$. 


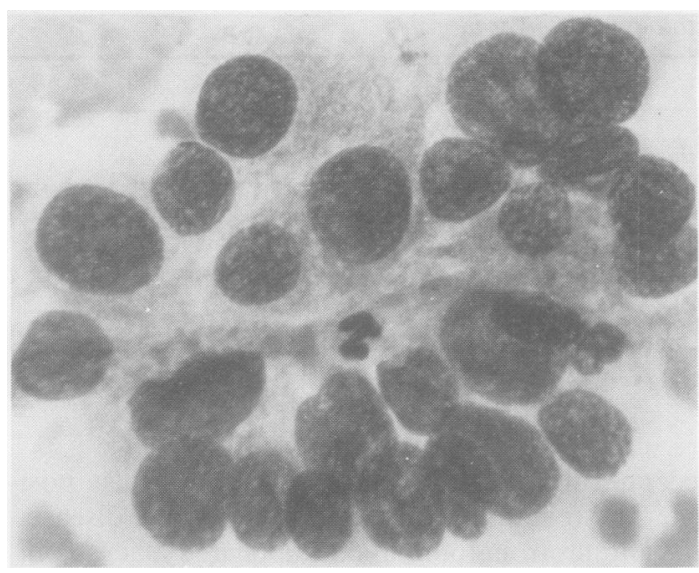

Fig. 3 Well differentiated hepatocellular carcinoma. Fine needle aspiration of liver. Leishman. Original magnification $\times 160$. Enlarged $\times 5$.

taken two years after faise positive aspiration results, did not show any tumour.

\section{FINE NEEDLE ASPIRATION PROCEDURE}

There were no complications attributable to the procedure. It was well tolerated by the patients, who complained of little pain and agreed to a second aspiration when necessary. If the initial aspiration yielded macroscopic blood in the syringe a second aspiration was performed at a different site (with the exception of the one patient described above) because experience showed that a bloody specimen usually contained few liver cells. Two patients had aspirations on two separate occasions because the

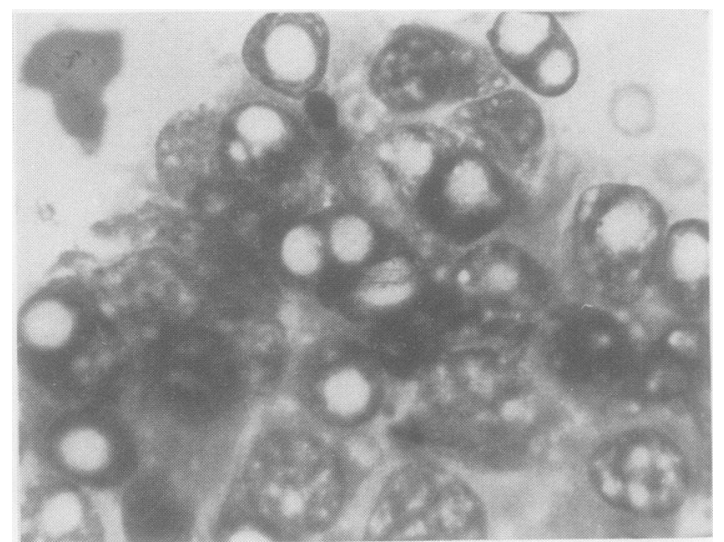

Fig. 4 Fine needle aspiration of liver from hepatocellular carcinoma which consisted almost entirely of vacuolated tumour cells (serum $\alpha$-fetoprotein positive). Leishman. Original magnification $\times 160$. Enlarged $\times 5$. first specimen was atypical but not diagnostic. The second specimen was diagnostic of hepatocellular carcinoma in one and contained anaplastic tumour cells in the other patient.

\section{CYTOLOGY}

Aspirates from benign liver contained fewer cells than aspirates from liver tumours. The benign hepatocytes are seen in regularly arranged monolayered sheets of polygonal cells with round or oval nuclei (Fig. 1). Variation in nuclear size, multinucleation, and prominent nucleoli are common and particularly pronounced in the diseased liver. Cytoplasm is abundant and appears finely granular with the Romanovsky stain. Bile pigment may appear in the cytoplasm as dark blue granules. Bile duct epithelium is often present and it is seen as clusters or tubular formations of small cuboidal or columnar cells (Fig. 2).

The aspirates reported as malignant nearly all contained many cells which were crowded together in such thick clusters that detailed morphology could be determined only from thinner areas at the periphery and between clusters. Malignant cytological characteristics of increased cell size, raised nuclear to cytoplasmic ratio, anisonucleosis, and macronucleoli were particularly striking. Cytoplasmic and nuclear vacuolation were common but were also seen in benign liver specimens. In hepatocellular carcinoma the tumour cells usually show some resemblance to benign hepatocytes in the quality of the cytoplasm and cellular arrangement. ${ }^{5-\varphi}$

The specimens reported as diagnostic of hepatocellular carcinoma were of two cytological types. Some were well differentiated and moderately well differentiated tumours in which the cells were usually small as well as numerous and many were arranged in tight clusters (Fig. 3). A consistently high nuclear to cytoplasmic ratio distinguished these cells from dysplasia. One hepatocellular carcinoma in this category consisted entirely of vacuolated cells (Fig. 4). The second type contained strikingly pleomorphic cells (Fig. 5). In these multinucleation was frequent and the cells were less cohesive.

The aspirates reported as consistent with hepatocellular carcinoma could be classified as poorly differentiated. The tumour cells were loosely arranged and many had no cytoplasm (Fig. 6). The diagnosis depended on a few clusters of better differentiated cells which resembled hepatocytes and might be seen in only a few areas of a slide, which was dominated by poorly differentiated tumour cells. Pleomorphism and multinucleation were not generally a feature of this group.

The two anaplastic aspirations which were 


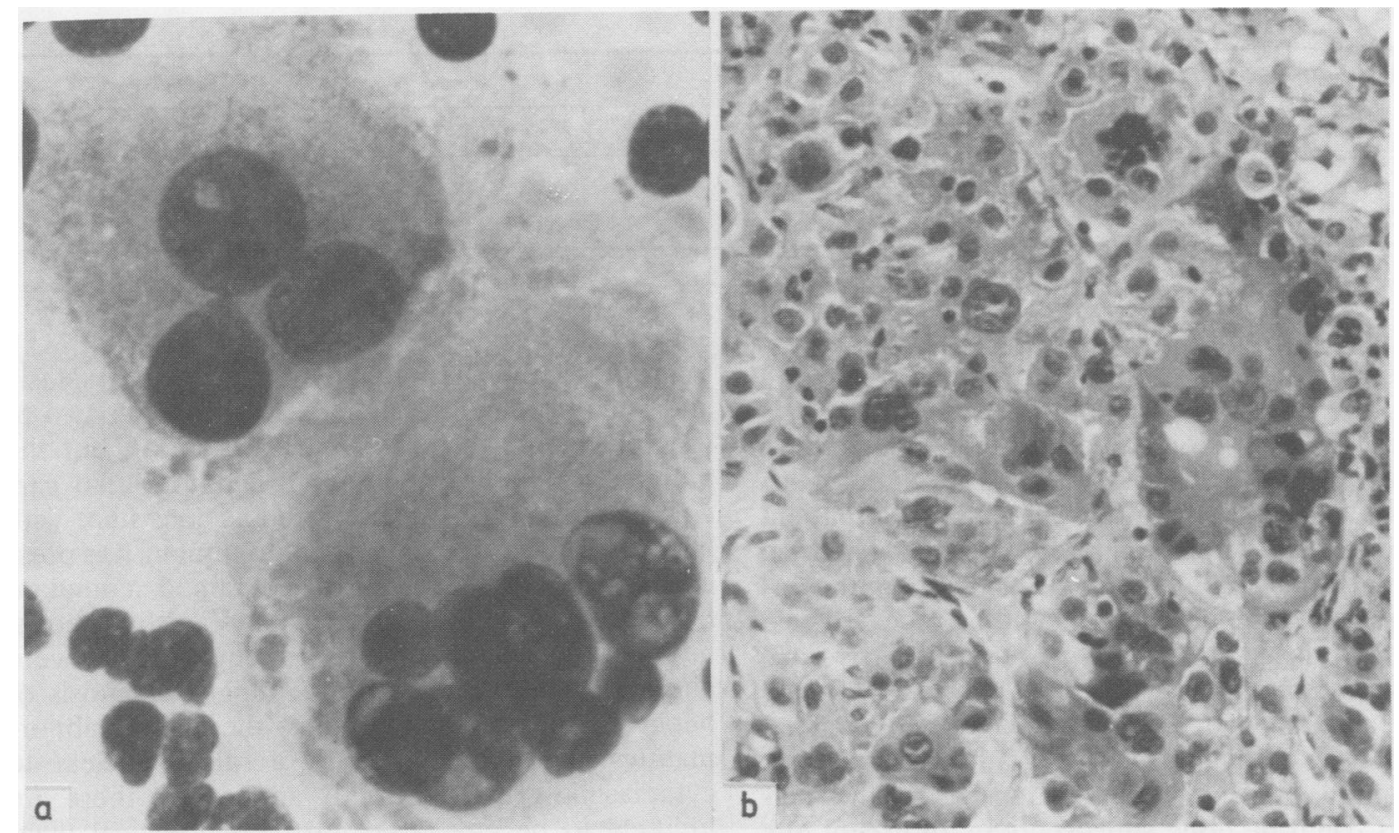

Fig. 5 Hepatocellular carcinoma with strikingly pleomorphic multinucleate cells. (a) Fine needle aspiration of liver. Leishman. Original magnification $\times 160$. Enlarged $\times 5$. (b) Histological section of liver biopsy. Haematoxylin and eosin. Original magnification $\times 63$. Enlarged $\times 5$.

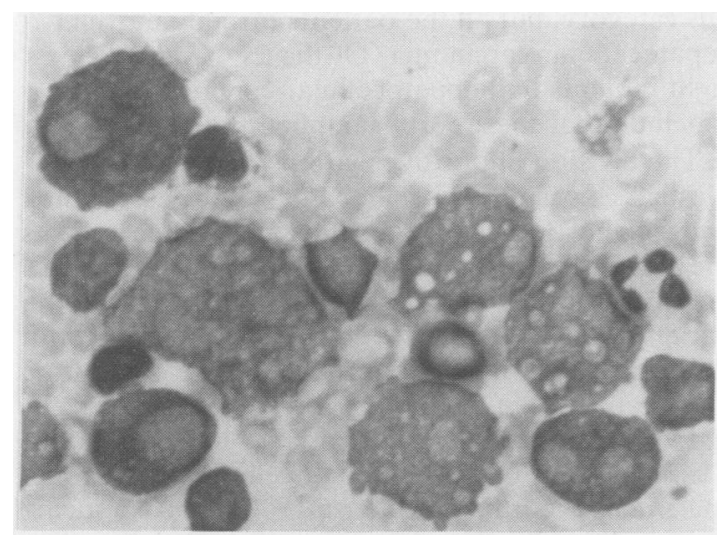

Fig. 6 Undifferentiated malignant cells which dominated this fine needle aspiration of liver from a patient with hepatocellular carcinoma (serum $\alpha$-fetoprotein positive). A few groups of differentiated tumour cells (not illustrated) permitted a report of consistent with hepatocellular carcinoma. Leishman. Original magnification $\times 160$. Enlarged $\times 5$. confirmed as hepatocellular carcinomas by positive $\alpha$-fetoprotein results consisted of malignant nuclei without cytoplasm or cellular cohesion. In the absence of cytoplasmic or structural qualities the diagnosis of hepatocellular carcinoma could not be confirmed.

Three specimens illustrated the problem of distinguishing between dysplasia and well differentiated hepatocellular carcinoma in cytological material. These were hypercellular but well differentiated. Two were reported as atypical because the nuclear to cytoplasmic ratio was not sufficiently high for firm diagnoses of hepatocellular carcinoma. One of these patient's hepatocellular carcinoma was confirmed by a positive $\alpha$-fetoprotein result and the other by histological biopsy. The third contained many abnormal bare nuclei and was wrongly reported during the first year of the study as consistent with hepatocellular carcinoma.

\section{ASCITIC FLUID}

Review of 89 patients with hepatocellular carcinoma showed that $64(71.9 \%)$ of them had ascites; paracentesis was carried out on 49 of these patients (Table 4). 
Table 4 Ascitic fuid from patients with hepatoma

\begin{tabular}{llllll}
\hline Appearance & $\begin{array}{l}\text { No of } \\
\text { specimens }\end{array}$ & Cytology & & & \\
\cline { 2 - 6 } & & Tumour cells & Atypical & Negative & Not done \\
\hline Bloody & 17 & 1 & - & 12 & 4 \\
Clear & 32 & 1 & 2 & 25 & 4 \\
Total & 49 & 2 & 2 & 37 & 8 \\
\hline
\end{tabular}

\section{Discussion}

Fine needle aspiration has been used extensively in clinical practice in Sweden since $1951,{ }^{10-12}$ but it has been little used in Africa. ${ }^{1314}$ This simple, outpatient procedure was well tolerated by the Gambian patients in this study. There were no apparent complications and the procedure could be repeated easily if necessary. The technique is particularly suitable where the support facilities necessary for histological biopsy are not available. The Gambian patients generally present with advanced disease. The tumour mass is large and extensive and the aspirations could be done subcostally in all except one patient.

Of 151 patients on whom fine needle aspiration was performed there was only one failure to obtain an adequate specimen. Hepatic malignancy was present in 133 of the 151 patients diagnosed by a combination of aspiration cytology, serum $\alpha$-fetoprotein, liver scan, and histological biopsy and the disease followed the expected course. The cytology was reported as malignant in $117(88.0 \%$ of the patients with hepatic malignancy). There was one false positive finding among the 117 cytological diagnoses of malignancy, which gives a predictive value $^{15}$ of positive diagnosis (true positives divided by the sum of true positives and false positives) of $99.1 \%$. There were 17 false negative results if the inadequate specimen, the two patients with benign aspiration who had metastatic carcinoma, and the six atypical reports are included, which give a predictive value of a negative result (true negatives divided by the sum of false negatives and true negatives) of $51.4 \%$. If the inadequate and atypical reports are excluded the 10 false benign reports make the predictive value of a benign report $64 \cdot 3 \%$.

The value of the cytological diagnosis is shown by the high proportion of correct positive diagnoses and the small number of equivocal (six atypical) diagnoses. The limitation of cytodiagnosis is illustrated by the one false positive report as well as the six atypical reports. Most specimens can be classified as benign or malignant without difficulty using only basic cytological criteria, but there will be a few specimens from which it may not be possible to dis- tinguish reliably between hyperplasia or dysplasia and hepatocellular carcinoma. In this series two of the specimens were classified as atypical, but the patients had well differentiated hepatocellular carcinoma and a third was reported as consistent with hepatocellular carcinoma when no tumour was present. These three aspirates contained abundant hepatocytes with nuclear atypia and anisonucleosis, but overt nuclear characteristics of malignancy were absent. If the principle of avoiding a diagnosis of hepatocellular carcinoma unless the nuclear abnormalities are accompanied by a raised nuclear to cytoplasmic ratio ${ }^{16}$ is strictly adhered to there are unlikely to be any false positive cytological diagnoses but there may be a small proportion of false negative (atypical) reports. Further experience, tumour markers, special staining of bile canaliculi, ${ }^{17}$ or morphometry may elucidate this grey area, but the test would no longer be simple and quick. Caution was exercised when samples contained only a few cells with nuclear characteristics of malignancy because it is known that considerable nuclear atypia may be seen in benign liver disease and particularly in dysplasia. ${ }^{16}$ Five of the six atypical reports were in this category, but all the patients turned out to have hepatocellular carcinoma. Of the 27 benign reports eight patients had hepatocellular carcinoma and we conclude that these were sampling errors.

The division of positive cytology reports into anaplastic, consistent with hepatocellular carcinoma, and diagnostic of hepatocellular carcinoma reflects the degree of differentiation in the specimen. This may vary throughout a tumour as illustrated by the patient who had fine needle aspiration from both right and left hypochondria, showing anaplastic malignant cells in one and moderately well differentiated hepatocellular carcinoma in the other. Classification of the hepatocellular carcinoma specimens according to their morphological appearances subdivides the aspirates into well and moderately well differentiated, pleomorphic, poorly differentiated, and anaplastic. The first three types have also been described by Tao et $a^{9}$ in their description of fine needle aspiration of 12 hepatocellular carcinomas. They found the cytomorphological features of hepatocellular carcinoma sufficiently dis- 
tinctive from metastatic tumour to be diagnostic whereas in this larger series there were seven anaplastic tumours which could not be typed.

Serum $\alpha$-fetoprotein results were positive ( $>1000$ $\mu \mathrm{g} / \mathrm{l})$ in 76 of the 125 patients with hepatocellular carcinoma $(60 \cdot 8 \%)$. The ratio of $\alpha$-fetoprotein positive to negative results was $41: 23$ in the better differentiated (diagnostic) specimens and 24:21 in the less well differentiated tumours (consistent with hepatocellular carcinoma). This could be interpreted as evidence that $\alpha$-fetoprotein secretion is more common in well differentiated hepatocellular carcinoma, but on the other hand the two anaplastic hepatomas were $\alpha$-fetoprotein positive. Studies in $\operatorname{man}^{18}$ and with cultured cells ${ }^{19}$ have related $\alpha$-fetoprotein synthesis to tumour dedifferentiation. Firm conclusions should not be drawn from the aspiration samples in view of their relatively small size and the variation expected within tumours. Fine needle aspiration was particularly valuable when hepatocellular carcinoma was suspected clinically but the $\alpha$-fetoprotein was negative, as shown by the 44 positive cytological diagnoses among 49 $\alpha$-fetoprotein negative patients with hepatocellular carcinoma. Aspiration was used more freely in $\mathrm{HBsAg}$ positive patients than in $\mathrm{HBsAg}$ negative patients even if their hepatomegaly could be accounted for by benign disease because of their high risk of developing hepatocellular carcinoma..$^{20}$

The isotope scan was a useful diagnostic aid but it was unnecessary for guidance of fine needle aspiration because of the advanced extent of the disease in the Gambian patients. A subcostal approach was used in all except one patient.

The poor diagnostic value of ascitic fluid examination is illustrated by the confident identification of tumour cells in only two of 49 patients with hepatocellular carcinoma. This was a similar finding to that of Reynolds et al, ${ }^{21}$ who found tumour cells in the ascitic fluid of only one patient of 25 with hepatocellular carcinoma. It is necessary for the tumour to have spread through the liver capsule or to have metastasised on the peritoneum for malignant cells to be present in the ascitic fluid. The absence of tumour cells confirms that peritoneal deposits of hepatocellular carcinoma are rare $^{22}$ and that the ascites is more commonly due to portal venous obstruction.

There are few reports of the use of fine needle aspiration for cytological diagnosis of hepatocellular carcinoma, ${ }^{91314}$ although the technique is widely used for sampling metastatic tumour in the liver with the guidance of imaging techniques. ${ }^{23-27}$ The procedure is particularly suitable for countries where medical resources are limited as in parts of South Africa and south east Asia, where hepatocellular carcinoma is common. Complications such as haemorrhage, peritonitis, or needle tract deposition of tumour are rare $\mathrm{r}^{232-31}$ and usually attributed to use of needles wider than $0.8 \mathrm{~mm}^{30}$; wide bore needle biopsy of hepatocellular carcinoma is relatively hazardous because of the vascular character of the tumour. ${ }^{2132}$ Treatment of hepatocellular carcinoma in developing countries is limited $^{8}$ and accurate diagnosis to exclude treatable conditions is therefore of particular importance. This paper shows the value of fine needle aspiration for cytological diagnosis of hepatocellular carcinoma in a country where the disease is prevalent.

We thank Professor T Chard and Mrs M Kitau of the Department of Obstetrics and Gynaecology, St Bartholomew's Hospital, London, and Mr Keith Williams of the Medical Research Council Laboratories, Fajara, The Gambia, for the serum $\alpha$-fetoprotein estimations. We are also grateful to Professor Robert L Peters, Dr Ashley Price, and Professor Gerard Slavin for interpretation of the histological biopsies.

\section{References}

' Doll R, Payne P, Waterhouse J. Cancer incidence in five continents. Volume I. Berlin: Springer Verlag, 1966.

${ }^{2}$ Crawley JCW, Ajdukiewicz AB, Bassett N, Cronquist AG, Veal $\mathbf{N}$. A radioisotope scanner for use in developing countries. Medical radionuclide imaging. Vienna: International Atomic Energy Agency, 1981.

${ }^{3}$ Leek AE, Ruoss CF, Kitau MJ, Chard T. Maternal plasma alfafetoprotein levels in the second half of normal pregnancy: relationship to fetal weight and maternal weight and parity. $\mathrm{Br}$ J Obstet Gynaecol 1975;82:669-73.

${ }^{4}$ Department of Health and Social Security. Code of practice for the prevention of infection in clinical laboratories and postmortem rooms. London: Her Majesty's Stationery Office, 1978.

s Anthony PP. Primary carcinoma of the liver: a study of 282 cases in Ugandan Africans. J Pathol 1973;110:37-48.

- Okuda K, Peters RL. Hepatocellular carcinoma. New York: John Wiley and Sons Ltd, 1976.

' Anthony PP. Tumours of the liver. In: Anthony PP, Woolf N, eds Recent advances in histopathology. London: Churchill Livingstone, 1978.

" Kew MC. Hepatocellular carcinoma. Postgrad Med J 1983;59(suppl 4), 78-87.

" Tao LC, Ho CS, McLoughlin MJ, Evans WK, Donat EE. Cytologic diagnosis of hepatocellular carcinoma by fine-needle aspiration biopsy. Cancer 1984;53:547-52.

${ }^{10}$ Zajicek J. Aspiration biopsy cytology, part 2. Basel: S Karger, 1979.

" Frable WJ. Fine needle aspiration biopsy: a review. Hum Pathol 1983;14:9-28.

${ }^{12}$ Fox $\mathrm{CH}$. Innovation in medical diagnosis - the Scandinavian curiosity. Lancet 1979; i: 1387-8.

${ }^{13}$ Brits CJ. Liver aspiration cytology. S Afr Med J 1974;48:220714.

${ }^{14}$ De Cock KM, Gatei DG, Shah MV. Aspiration cytology in the diagnosis of liver cancer. East Afr Med J 1981;58:636-40.

15 Vecchio TJ. Predictive value of a single diagnostic test in an 
unselected population. N Engl J Med 1966;274:1171-3.

${ }^{16}$ Anthony PP, Vogel CL, Barker LF. Liver cell dysplasia: a premalignant condition. J Clin Pathol 1973;26:217-23.

${ }^{17}$ Ekelund P, Wasastjerna C. Cytological identification of primary hepatic carcinoma cells. Acta Med Scand 1971;189:373-5.

${ }^{18}$ Alpert E, Hershberg R, Schur PH, et al. Alpha-fetoprotein in human hepatoma: improved detection in serum and quantitative studies using a new sensitive technique. Gastroenterology 1971;61:137-43.

${ }^{14}$ Abelev GI. Alpha-fetoprotein in ontogenesis and its association with malignant tumours. Adv Cancer Res 1971;14:295-357.

${ }^{20}$ Hadziyannis SJ. Hepatocellular carcinoma and type B hepatitis. Clin Gastroenterol 1980;9:117-54.

${ }^{21}$ Reynolds TB. Diagnostic methods for hepatocellular carcinoma. In: Okuda K, Peters RL, eds. Hepatocellular carcinoma. New York: J Wiley and Sons Ltd, 1976.

${ }^{22}$ Chan CH. Primary carcinoma of the liver. Med Clin North Am 1975;59:989-94.

${ }^{23}$ Lundquist A. Fine needle aspiration for cytodiagnosis of malignant tumour in the liver. Acta Med Scand 1970;188:465-70.

${ }^{24}$ Schwerk WB, Schmidt-Moormann P. Ultrasonically guided fine needle biopsies in neoplastic liver disease. Cancer 1981;48: 1469-77.

${ }^{25}$ Tao LC, Donat EE, Ho CS, McLoughlin MJ. Percutaneous fine needle aspiration biopsy of the liver. Acta Cytol
1979; 23:287-91.

${ }^{26}$ Porter B, Karp W, Forsberg L. Percutaneous cytodiagnosis of abdominal masses by ultrasound guided fine needle aspiration biopsy. Acta Radiol (Diagn) (Stockh) 1981;22:663-7.

${ }^{27}$ Zornoza J, Wallace S, Ordonez N, Lukeman J. Fine needle aspiration biopsy of the liver. American Journal of Roentgenology 1980;134:331-4.

${ }^{28}$ Schulz TB. Fine needle aspiration biopsy of the liver complicated with bile peritonitis. Acta Med Scand 1976;199:141-2.

${ }^{29}$ Ferrucci JT, Wittenberg J, Margolies MN, Carey RW. Malignant seeding of the tract after thin needle aspiration biopsy. Radiology 1979; 130:345-6.

${ }^{30}$ Sakurai M, Seki K, Okamura J, Kuroda C. Needle tract implantation of hepatocellular carcinoma after percutaneous liver biopsy. Am J Surg Pathol 1983; 7:191-5.

${ }^{31}$ Riska H, Friman C. Fatality after fine needle aspiration biopsy of the liver (Letter) $\mathrm{Br}$ Med J 1975; i:517.

${ }^{32}$ Conn HO. Nuclide scanning, ultrasonography and liver biopsy in the diagnosis of hepatic tumours. Clin Gastroenterol 1976; 5:665-80.

Requests for reprints to: Dr EA Hudson, Department of Histopathology, Northwick Park Hospital and Clinical Research Centre, Watford Road, Harrow, Middlesex HA1 3UJ, England. $\stackrel{0}{3}$ 